\title{
Sampling Hard to Reach Populations: A Survey on Forced Migration During Maoist Insurgency in Nepal
}

Prakash Adhikari ${ }^{*}$

Tags: nepal, internally displaced persons, forced migration

DOI: $10.29115 /$ SP-2013-0013

\section{Survey Practice}

Vol. 6, Issue 3, 2013

\begin{abstract}
Most research on forced migration acknowledges the fact that acquiring accurate data on refugees and internally displaced persons (IDPs) is challenging, if not impossible. With the help of a national human rights organization, embedded in communities across Nepal, I employed a weighted multi-stage cluster sampling technique to survey over 1800 individuals from 56 village development committees (VDCs) drawn from 11 of the 75 districts of Nepal to study individual coping behaviors during a decade-long insurgency in Nepal. This national sample represents districts that were hard-hit during the conflict, all three topographical regions, all five development regions, and both rural and urban parts of Nepal.
\end{abstract}

\section{INTRODUCTION}

Forced migrants typically include two types of individuals, refugees who cross an international border and internally displaced persons (IDPs) who flee their homes but do not cross the border into another country. Scholars in the field acknowledge that it is extremely difficult to obtain accurate data on forced migration caused by conflict (Crisp 1999). This research provides an account of this issue with a description of the problems one faces in enumerating forced migrants, the role that human rights organizations play in reaching such populations and the sampling method used in the present survey (see Adhikari 2012a for details).

\section{THE MAOIST INSURGENCY IN NEPAL AND CHALLENGES OF IDENTIFYING FORCED MIGRANTS}

Nepal went through a decade of Maoist insurgency beginning in 1996, in which over 13,000 people were killed, thousands displaced and many more disappeared. Similar to other conflict situations, figures on displacement during the Maoist insurgency in Nepal vary dramatically. Only one organization, namely the Informal Sector Service Center (INSEC), a national human rights organization operating throughout Nepal since 1988, made a concerted effort to document and verify displacement figures. Their work was conducted on a subnational, district by district basis. According to INSEC, 
50,356 people were displaced from across the 75 districts by the end of 2004 . There is strong reason to believe that the data collected by INSEC is the most reliable and accurate. Because INSEC operates in all 75 districts of Nepal, the data collected by their district offices are more reliable than other national estimates. INSEC was the only organization to collect data on displacements at the level of the village development committee (VDC), the smallest administrative unit in Nepal.

\section{SAMPLING FRAME AND METHOD}

The sampling frame used in this study is INSEC's list of people displaced from each district between 1996 and 2006 due to conflict. The full data set gathered in this study consists of a national sample of 1,804 respondent households from 56 VDCs drawn from 11 districts of Nepal, plus the capital of Kathmandu. Households were selected from 226 sampling units, called wards, from across these 11 districts. The survey was also administered in Kathmandu where many of the internally displaced persons fled. A weighted multistage cluster sampling technique was used to go from region, to district, to VDC, to ward level and then two samples were randomly drawn ? one of individuals at the ward level and another of displaced persons originating from those wards. Use of wards as the sampling units has the advantage of offering a paired design of individuals who decided to stay and those who decided to leave within the same contextual environment.

The sampling method involved multiple stages because I sought to ensure that the sample represented (a) districts that were hard-hit during the conflict, (b) all three topographical regions, (c) all five development regions, and (d) both rural and urban parts of the country. In the first stage, all districts that had recorded at least 500 casualties or 500 displacements during the conflict were selected. The selection criteria were based on secondary data provided by INSEC on the number of people killed and displaced from each district. A total of 19 districts met this threshold. Four of the five economic development regions contained exactly two districts that met the threshold, and varied topographically, so these eight were chosen. The remaining districts were in the midwestern region where the fighting originated. One district was randomly chosen from each of the three topographical regions. This resulted in a total of 11 districts, plus Kathmandu, being retained for sampling.

The total number of interviewees was set at 1,500 for the 11 districts, with a target of 1000 displaced and 500 non-displaced, with the remaining 304 interviewees coming from the capital. The number of displaced was further divided into two groups: 500 interviewees still displaced and 500 interviewees that had returned home. In each of the 11 districts, the target number of interviewees was determined by the proportion of displaced identified by INSEC in each district. Each district is divided into VDCs, with each VDC further subdivided into nine wards. Only VDCs with 10 or more displaced persons were used in the sampling of respondents. Out of several VDCs 
meeting this threshold in each district, five VDCs were randomly selected, and the targeted number of respondents was determined by the proportion of displaced in each of these VDCs. Next, the targeted number of respondents from each of the five VDCs were randomly sampled from the wards in proportion to the number of displaced in each ward. Displaced respondents, which included both males and females, were randomly selected from a list maintained by INSEC of all displaced persons originating from the wards. The 500 non-displaced respondents were randomly selected from the same districts/VDCs/wards in which the displaced originated. Target numbers of non-displaced from each ward were based on the same proportions used for sampling the displaced.

Table 1 lists the 11 districts identifying the economic development region and topographic zone where each is located, and the target number (and actual number) of displaced respondents based on the proportion of displaced originating in each of the districts out of the total number of displaced persons identified in the eleven districts. So, for example, Rolpa had 1817 displaced out of the total 17,386 displacements in the 11 districts, resulting in a target number of $105(1817 / 17,386 \times 1000=105)$ displaced interviewees, and 52 $(0.5 \times 105=52)$ non-displaced. Rolpa is further broken down into the five randomly selected VDCs. Based on the proportion of actual displacement in each of the five VDCs, a target number of interviewees is given, along with the actual number of displaced persons interviewed and the number of non-displaced interviewed.

\begin{tabular}{|c|c|c|c|c|c|c|}
\hline \multicolumn{7}{|c|}{ Economic Development Regions } \\
\hline \multirow{4}{*}{ 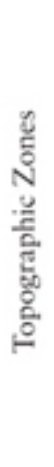 } & & Far West & Midwest & Western & Central & East \\
\hline & Mountains & $\begin{array}{l}\text { Bajura: } \\
84(70)\end{array}$ & $\begin{array}{l}\text { Kalikot: } \\
203(218)\end{array}$ & & & $\begin{array}{l}\text { Taplejung: } \\
44(50)\end{array}$ \\
\hline & Hills & & $\begin{array}{l}\text { Rolpa: } \\
\text { 105(96) } \\
\quad \text { Thawang } \\
\text { Kureli } \\
\text { Uwa } \\
\text { Mirul } \\
\text { Bhawang }\end{array}$ & $\begin{array}{l}\text { Lamjung: } \\
49(47)\end{array}$ & $\begin{array}{l}\text { Ramechhap: } \\
73(88)\end{array}$ & \\
\hline & Plains & $\begin{array}{l}\text { Kailali: } \\
118(124)\end{array}$ & $\begin{array}{l}\text { Bardiya: } \\
94(108)\end{array}$ & $\begin{array}{l}\text { Kapilbastu: } \\
152(151)\end{array}$ & $\begin{array}{l}\text { Chitwan: } \\
48(43)\end{array}$ & $\begin{array}{l}\text { Jhapa: } \\
30(17)\end{array}$ \\
\hline
\end{tabular}

Rolpa as an example of the sampling process.

\begin{tabular}{lcccc}
\hline VDCs & $\begin{array}{l}\text { Proportion of actual } \\
\text { displacement in five } \\
\text { randomly selected VDCs }\end{array}$ & $\begin{array}{l}\text { Target number } \\
\text { of interviewees }\end{array}$ & $\begin{array}{l}\text { Actual number } \\
\text { interviewed }\end{array}$ & $\begin{array}{l}\text { Actual non-displaced } \\
\text { interviewed }\end{array}$ \\
\hline Thawang & 0.27 & 28 & 19 & 28 \\
Kureli & 0.26 & 27 & 37 & 12 \\
Uwa & 0.23 & 24 & 20 & 11 \\
Mirul & 0.20 & 21 & 15 & 7 \\
Bhawang & 0.03 & 3 & 5 & 60 \\
Total & $100 \%$ & 105 & 96 & 2 \\
\hline
\end{tabular}

Table 1 Eleven districts selected for sampling with target (and actual) number of respondents interviewed. 
The target and actual number of interviewees differs somewhat for each VDC because INSEC's and the Nepali government's identification and documentation of displaced persons as well as people injured, killed, and disappeared was still ongoing at the time the interviews were conducted, so the identification of conflict-induced displacement was still somewhat in flux. For example, while INSEC had information on the number of people displaced from each VDC, a complete list of names was not always available, and on occasion, the randomly drawn subject could not be found when enumerators approached the identified households. Also, because it was monsoon season and farmers were engaged in planting their fields, some declined to respond. Under these difficulties, along with time and resource constraints that sometimes prevented repeated attempts to interview subjects, the targeted number could not always be reached. With the overall district targets in mind, VDC targets were sometimes exceeded in villages where the number of available displaced subjects appeared to exceed the original INSEC figures.

There are a total 51 VDCs in Rolpa, from which five, which produced 10 or more IDPs, were selected; 363 people were displaced from these five VDCs with 99 coming from Thawang, 94 from Kureli, 85 from Uwa, 74 from Mirul, and 11 from Bhawang. The targeted number of respondents from each of the five VDCs was determined by the proportion of displaced in each of the VDCs (e.g., Thawang: $99 / 363 \times 105=28$ ). Next, the targeted number of the non-displaced respondents from each of the five VDCs was randomly sampled from the wards in proportion to the number of displaced in each ward.

The main objectives of the survey are to study causes of displacement during the Maoist insurgency in Nepal and the ability of individuals to cope with their situations under conflict. ${ }^{1}$ During the survey, individuals were asked about the violence they experienced and whether they engaged in activities such as paying rent to the Maoists in order to help them stay in their homes. Individuals who experienced violence should be more likely to flee their homes. The more often individuals paid rent to the Maoists, the more likely they would be able to stay in their homes. Other coping activities included joining the Maoists by changing party affiliation, participating in protests and rallies and other political activities organized by the Maoists, and joining a community organization. Community organizations such as the community forest users group, mothers group, or small farmers development programs provided a mechanism for people to come together enabling them to cope with the difficulties of war. Table 2 reports results from difference of means tests between displaced and non-displaced individuals for these various measures. 
Table 2 Differences in the means of independent variables for non-displaced and displaced samples of individuals.

\begin{tabular}{llllc}
\hline Variables & $\mathrm{n}$ & Mean (non-displaced sample) & Mean (displaced sample) & Mean difference \\
Actual violence & 1804 & 0.694 & 0.921 & $-0.227^{* *}$ \\
Times rent paid & 1664 & 4.426 & 3.746 & $0.680^{*}$ \\
Join Maoist party & 1781 & 0.252 & 0.167 & $0.085^{* *}$ \\
Participate & 1781 & 0.220 & 0.176 & $0.044^{* *}$ \\
Community organizations & 1804 & 0.715 & 0.667 & $0.048^{*}$
\end{tabular}

Note: The $\mathrm{n}$ varies due to random missing data.

${ }^{* *}=$ Significant at the 0.05 level or better, ${ }^{*}=$ Significant at the 0.10 level.

\section{DISCUSSION}

The results in Table 2 confirm that violence affects displacement; those who fled their homes were more likely to have experienced violence against them than those who stayed in their homes. However, the results also suggest that individuals have a number of coping mechanisms that can be used to help them stay in their homes. Those who stayed in their homes were likely to pay rent to the Maoists more often, and were more likely to join the Maoist party, participate in the Maoist movement, and have a community organization in their village. These activities may have reduced the likelihood that individuals would be targeted by the Maoists, allowing them to stay behind while others fled.

This study reveals a number of interesting and useful lessons for future research in the field. Despite the challenges one faces in enumerating the hard-to-reach population of forced migrants and physical challenges posed by rough terrain, one can reach respondents with careful planning and thoughtful strategy. First, it was important to pretest my survey instrument before I actually administered it to the respondents. This gave me the opportunity not only to revise my survey instrument, but also to gauge the accessibility of the respondent population.

Second, it is vital that researchers become familiar with local geography and local language and culture, so my being from Nepal was an asset. Third, as a researcher, I had to be sensitive to the wartime suffering and experiences of the respondents. During the course of my research in Nepal, I traveled to several districts and spoke to many villagers. I presented myself as someone who was keen to understand the trauma that they underwent during the war and who was interested in knowing about their experiences. To my surprise, many people were willing to tell me their stories even if that meant just to release the pain they had been enduring.

Finally, one has also to be aware and familiar with local weather such as monsoon and harvesting season, especially when conducting research in developing countries like Nepal. I conducted most of my research during the summer and the monsoons arrived during my research. Most Nepalis are 
farmers and they return to their fields with the onset of the monsoon season. This made it extremely challenging to find the respondents further straining my already limited resources. If I had the opportunity to conduct another survey in Nepal or similar country and were able to choose the time, this would probably be in the winter when villagers would be less busy. 


\section{REFERENCES}

Adhikari, P. 2012a. "Role of Social Networks in Sampling Hard to Reach Population.” In Proceedings of the International Conference on Methods for Surveying and Enumerating Hard-toReach Populations. New Orleans, LA: American Statistical Association.

- - - 2012b. "The Plight of the Forgotten Ones: Civil War and Forced Migration." International Studies Quarterly 56 (3): 590-606.

- - . 2013. "Conflict-Induced Displacement, Understanding the Causes of Flight." American Journal of Political Science 57 (1): 82-89.

Adhikari, P., W.L. Hansen, and K.L. Powers. 2012. "The Demand for Reparations: Grievance, Risk and the Pursuit of Justice in Civil War Settlement." Journal of Conflict Resolution 56 (2): 183-205.

Adhikari, P., and S. Samford. n.d. "The Dynamics of the Maoist Insurgency in Nepal." In Studies in Comparative International Development. Accepted for publication.

Crisp, J. 1999. "Who Has Counted the Refugees? UNHCR and the Politics of Numbers.” New Issues in Refugee Research, Working Paper No. 12.

Informal Sector Service Center (INSEC). 2004. Nepal Human Rights Year Book. Kathmandu: INSEC. 